\title{
BULLETIN
}

\section{INTER NATI0 NAL}

DES

SOCIETTES DE LA GROIX-ROUGE

PUNLIE PAR LE

COMHTH INTHERNATIONAI

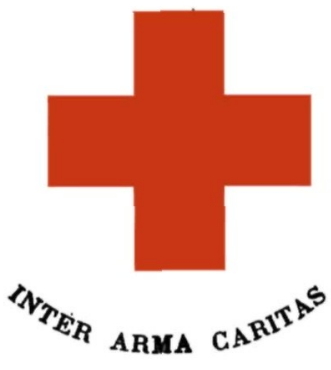

GENEVE

IMPRIMERIE I. SOULLIER, GITḱ, 19-21

JUIHIFT 1894 


\section{COMITÉ INTERNATIONAL}

Pour adresse: M. Gustave Moynıen, Président, à Genève (Suisse).

Les membres du Comite sont:

MN. Moynier, Gustave, président.

Ador, Gustave, Conseiller d'État, Vice-Président.

Odier, Edouard, Membre du Conseil des Etats, Secrétaire.

Appia, Louis, Dr méd.

D'Tspine, Adolphe, Dr méd., professeur à l'Université.

Favre, Camille, Colonel brigadier.

Ferrière, Frédéric, Dr-méd.

Gautier, Alfred, Professeur à l'Université et juge à la Cour de cassation.

\section{ADRESSES DES COMITÉS CENTRAUX}

ALLEMAGNE. - Comité central des associations allemandes de la Croix-Rouge. Wilhemstrasse, 73, à Berlin.

ARGentine (RÉpublique). - M. le Dr Pedro F. Roberts, président, pour la Société argentine de la Croix-Rouge,Victoria 723, à Buenos-Ayres.

AUTRICHE. - Société autrichienne de la Croix-Rouge. Herrengasse, 23, à Vieme.

BADE. - Comité général de la Société badoise de la CroixRouge. Herrenstrasse, 45, à Carlsruhe.

BAVIĖRE. - S. E. le Comte de Castell, président, pour le Comité central de la Société bavaroise pour les soins et l'assistance à fournir aux militaires blessés et malades en campagne, à Munich.

BELGIQUE. - Société belge de la Croix-Rouge, Rue de l'Arbre bénit, 97, à Bruxelles.

BULGARIE. - M. le $\mathrm{D}^{\mathrm{r}}$ Jetcheff, président de la Société bulgare de la Croix-Rouge, à Sofia.

CONG3. - Association congolaise et africaine de la CroixRouge, rue de Namur, 12, à Buruxclles.

DANEMARK. - M. le Président du Comité central danois de la Croix-Rouge, Bulowsvei, 24, à Copenhague.

ESPAGNE. - Société espagnole de la Croix-Rouge, Isabel la Catolica, 4 duplicado, pral. Madrid.

ÉTATS-UNiS. - Miss Clara Barton, présidente, pour la Société américaine de la Croix-Rouge, à Washington.

FRANCE. -- Société francaise de secours aux militaires blessés des armées de terre et de mer. Rue Matignon, 19, à Paris.

GRANDE BRETAGNE. - British National Society for Aid to the Sick and Wounded in war. Central Comité. 5, York Buildings, Adelphi, London.

GRĖCE. - M. Marc Benieri, gouverneur de la Banque de G rèce, président de la Société grecque de la Croix-Rouge, à Athènes.

(Voir la suite à la troisième page de cette couverture) 